\title{
Short communication: Phosphate transporter expression in Holstein cows
}

\author{
A. P. Foote, ${ }^{\star}$ B. D. Lambert, ${ }^{*} \dagger^{1}$ J. A. Brady, $\dagger$ and J. P. Muir $\dagger$ \\ *Department of Animal Sciences, Tarleton State University, Stephenville, TX 76402 \\ †Texas AgriLife Research, Stephenville, TX 76401
}

\section{ABSTRACT}

Phosphorus nutrition in cattle is increasingly becoming an important topic because excess dietary $\mathrm{P}$ is excreted in manure and can be washed into surface water, causing increased algal growth and eutrophication. However, little is known about the mechanism or regulation of $\mathrm{P}$ absorption in dairy cattle. Phosphorus transporters have been characterized in other species and homologous genes have been found to be expressed in bovine cell cultures. However, no other information is available regarding the active transport of phosphate in the digestive tract of cattle. The objective of this study was to determine the patterns of expression of a known phosphate transporter, NaPi-IIb, in 4 sections of the small intestine of Holstein cows. Ribonucleic acid was isolated from the duodenal, proximal jejunal, distal jejunal, and ileal mucosa of 20 Holstein cows. Relative amounts of NaPi-IIb mRNA expression were determined using real-time reverse-transcription PCR. Expression of NaPi-IIb was highest in the 2 distal sections and almost absent in the proximal sections. Expression did not differ between the 2 proximal sections or the 2 distal sections. These data suggest that a $\mathrm{Na}^{+}-$ dependent secondary active $\mathrm{P}$ transport system is not responsible for $\mathrm{P}$ absorption in the proximal portion of the bovine small intestine, whereas it does contribute to the $\mathrm{P}$ absorbed in the distal sections of the bovine small intestine.

Key words: phosphorus, NaPi-IIb, transport

\section{Short Communication}

Little is known about intestinal $\mathrm{P}$ absorption in beef and dairy cattle. In monogastrics, the duodenum and jejunum are the primary site of $\mathrm{P}$ absorption (Cross et al., 1990; Breves and Schroder, 1991; Danisi and Murer, 1991; Kayne et al., 2001). However, it has also been shown that the ileum of the rat can contribute up to $40 \%$ of the total absorbed P, likely due to a slower emp-

Received August 6, 2010.

Accepted January 12, 2011

${ }^{1}$ Corresponding author: blambert@tarleton.edu tying rate in the ileum compared with other intestinal sections (Kayne et al., 1993). Phosphate can be absorbed by both passive and active mechanisms (Cross et al., 1990; Kayne et al., 2001). Phosphate concentration in digesta must be high for passive diffusion to occur (Cross et al., 1990) and active transport is predominant at lower P concentrations; therefore, it is believed that passive diffusion occurs in the duodenum and proximal jejunum, whereas active $\mathrm{P}$ transport predominates in the distal jejunum and ileum.

The Na-dependent transporter responsible for secondary active transport of $\mathrm{P}$, known as NaPi-IIb, has been characterized in many species (Huber et al., 2000; Werner and Kinne, 2001; Murer et al., 2004; Yan et al., 2007). An homologous protein has been identified in the genome of Bos taurus (Helps et al., 1995) but has not been studied. Patterns of NaPi-IIb expression differ between species. Expression of NaPi-IIb in rats is highest in the ileum, intermediate in the jejunum, and almost absent in the duodenum (Radanovic et al., 2005). In chickens, $\mathrm{NaPi}-\mathrm{IIb}$ is expressed at highest quantities in the duodenum and lower quantities in the jejunum and ileum (Yan et al., 2007). In rabbits, it has been demonstrated that $\mathrm{Na}^{+}$-dependent absorption of $\mathrm{P}$ only occurs in the duodenum (Shirazi-Beechey, 1988).

The objective of this study was to determine the patterns of expression of a known phosphate transporter, $\mathrm{NaPi}-\mathrm{IIb}$, in 4 sections of the small intestine of dairy cattle to test the hypothesis that phosphate absorption in dairy cattle is accomplished and regulated by a similar mechanism as in other ruminants.

Tissue samples were collected from the duodenum, proximal jejunum, distal jejunum, and ileum of 20 mature Holstein cows immediately after harvest at a local commercial abattoir. Samples were immediately frozen in liquid $\mathrm{N}$ for transport to the laboratory and then stored at $-80^{\circ} \mathrm{C}$. Intestinal sections were thawed in boiling water for $5 \mathrm{~min}$ and the mucosa was scraped and homogenized in Tri Reagent RT (Molecular Research Center, Inc., Cincinnati, OH). Ribonucleic acid extractions were performed using the instructions provided by Molecular Research Center, Inc. After homogenization, phase separations were performed using bromoanisole. Ribonucleic acid was then precipitated 
Table 1. Primer and probe sets used for semiquantitative real-time PCR analysis of the NaPi-IIb phosphate transporter and GAPDH reference gene cDNA generated from intestinal mRNA

\begin{tabular}{|c|c|c|c|}
\hline Primer and probe & $\begin{array}{l}\text { Location on } \\
\text { template (bp) }\end{array}$ & Sequence & $\begin{array}{l}\text { Amplicon } \\
\text { size (bp) }\end{array}$ \\
\hline \multicolumn{4}{|c|}{ NaPi-IIb (NM_174661) } \\
\hline Forward & $603-622$ & 5'-GTCAGCATGGTGGCCTCCTC-3' & \multirow{2}{*}{144} \\
\hline Reverse & $726-746$ & 5'-CGCAAAGGCCCTTCTGAACTC-3' & \\
\hline \multicolumn{4}{|c|}{ GAPDH (NM_001034034) } \\
\hline Forward & $813-837$ & 5'-GGAGAAACCTGCCAAGTATGATGAG-3' & 129 \\
\hline
\end{tabular}

using isopropanol and a salt solution $(0.8 \mathrm{M}$ sodium citrate, $1.2 \mathrm{M} \mathrm{NaCl}$ ) and then washed twice with $75 \%$ ethanol (Chomczynski and Sacchi, 1987). Ribonucleic acid concentration and purity were determined using spectrophotometry. All RNA sample extracts were determined to have a high purity with 260:280 absorbance ratios greater than 2.0 and 260:230 absorbance ratios greater than 1.7 .

To synthesize cDNA, RNA was reverse transcribed using Transcriptor Reverse Transcriptase according to manufacturer's instructions (Roche Applied Science, Indianapolis, IN). Briefly, $0.5 \mu \mathrm{g}$ of RNA was combined with $1 \mu \mathrm{L}$ ( $60 \mu M$ final concentration) of random hexamer primers, $2 \mu \mathrm{L}$ of $5 \times$ Transcriptor reaction buffer, $1 \mu \mathrm{L}$ of deoxyribonucleotide triphosphate (dNTP; 10 $\mathrm{m} M$ each), $0.25 \mu \mathrm{L}$ of Protector RNase Inhibitor (40 $\mathrm{U} / \mu \mathrm{L}$, Roche Applied Science), $0.25 \mu \mathrm{L}$ of Transcriptor Reverse Transcriptase $(20 \mathrm{U} / \mu \mathrm{L}$, Roche Applied Science), and $3.5 \mu \mathrm{L}$ of RNase-free deionized water. The reverse transcription reactions were incubated at $25^{\circ} \mathrm{C}$ for $10 \mathrm{~min}$, followed by $55^{\circ} \mathrm{C}$ for $20 \mathrm{~min}$. Reactions were terminated by heating to $85^{\circ} \mathrm{C}$ for $5 \mathrm{~min}$. The reverse transcription reactions were then diluted to $20 \mu \mathrm{L}$.

Primer and probe sets (Table 1) for bovine NaPi-IIb and GAPDH (for use as a reference gene) were designed using AlleleID (Premier Biosoft International, Palo Alto, CA). To decrease error from amplification of genomic DNA, primer and probe sets were designed to span an exon-exon junction. Probes were labeled with $\mathrm{Cy} 5$ on the $5^{\prime}$ end and BHQ2 on the $3^{\prime}$ for fluorescence development by $5^{\prime}$ hydrolysis of the probe sequence. To determine the relative concentration of the $\mathrm{NaPi}-\mathrm{IIb}$ gene, cDNA was amplified using a Roche LightCycler 480 system (Roche Applied Science). The PCR reaction $(5 \mu \mathrm{L})$ contained $1 \mu \mathrm{L}$ of cDNA solution, $0.25 \mu \mathrm{L}$ of primer $\operatorname{mix}(10 \mathrm{~m} M$ each), $0.25 \mu \mathrm{L}$ of probe $(10$ $\mathrm{m} M), 2.5 \mu \mathrm{L}$ of real-time PCR master mix, and $1 \mu \mathrm{L}$ of $\mathrm{H}_{2} \mathrm{O}$. The real-time PCR master mix consisted of $1 \mathrm{~m} M$ EDTA (pH 8.0), $10 \mathrm{~m} M \mathrm{MgCl}_{2}, 80 \mathrm{~m} M$ Tris-Cl (pH 9.0), $50 \mathrm{~m} M \mathrm{KCl}, 1.2 \mathrm{~m} M$ deoxyuridine triphosphate (dUTP), $0.4 \mathrm{~m} M$ deoxyadenosine triphosphate
(dATP), $0.4 \mathrm{~m} M$ deoxycytidine triphosphate (dCTP), $0.4 \mathrm{~m} M$ deoxyguanosine triphosphate (dGTP), 0.002 $\mathrm{U} / \mu \mathrm{L}$ of LightCycler Uracil-DNA Glycosylase (Roche Applied Science), 1/10,000 total volume of Sybr Green I nucleic acid stain (Invitrogen, Carlsbad, CA), and 0.2 $\mathrm{U} / \mu \mathrm{L}$ of Platinum Taq DNA Polymerase (Invitrogen). The PCR conditions included a denaturing step $\left(95^{\circ} \mathrm{C}\right.$ for $10 \mathrm{~min}), 45$ cycles of amplification including denaturing $\left(95^{\circ} \mathrm{C}\right.$ for $\left.10 \mathrm{~s}\right)$, annealing $\left(60^{\circ} \mathrm{C}\right.$ for $\left.10 \mathrm{~s}\right)$, and elongation $\left(72^{\circ} \mathrm{C}\right.$ for $\left.10 \mathrm{~s}\right)$. A melt curve was included $\left(37^{\circ} \mathrm{C}\right.$ to $95^{\circ} \mathrm{C}$ at $0.15^{\circ} \mathrm{C} / \mathrm{s}$ with continuous fluorescence acquisition) to ensure the production of a single PCR product. Ratios of target to control genes were deter-

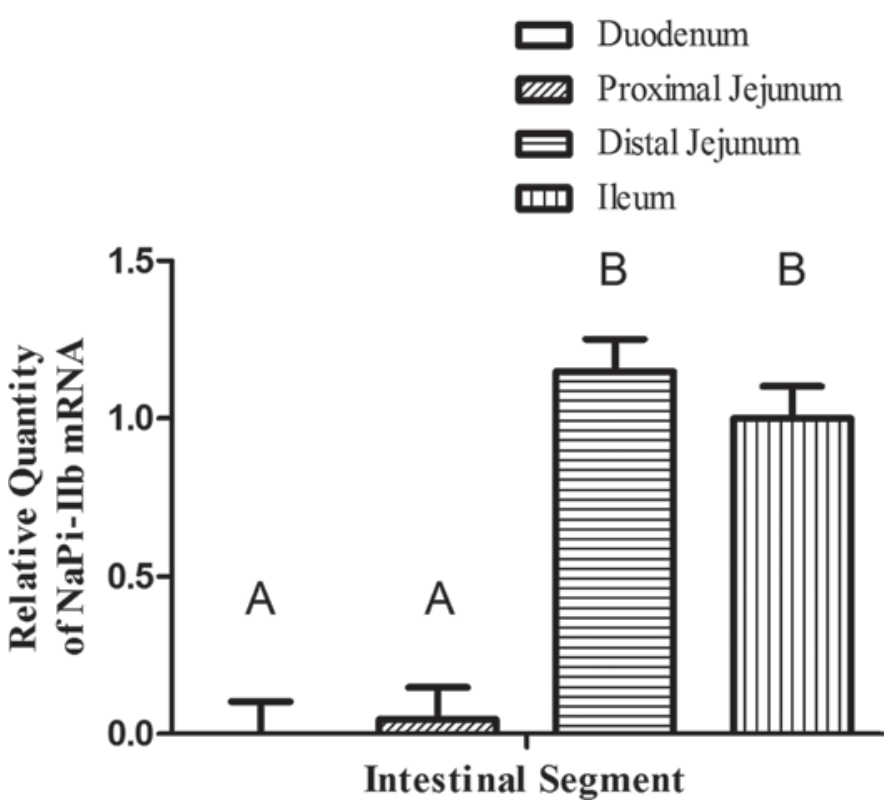

Figure 1. Relative quantity of the phosphate transporter NaPi-IIb in the duodenum $(\mathrm{n}=19)$, proximal jejunum $(\mathrm{n}=17)$, distal jejunum $(\mathrm{n}=18)$, and ileum $(\mathrm{n}=19)$ of Holstein cows. Bars represent the mean \pm SEM of the relative quantity of NaPi-IIb (normalized to GAPDH expression). Bars with different letters differ $(P<0.0001)$. The number of experimental units varied due to the timing of collecting the intestinal samples, fecal samples, and operation of the abattoir. 


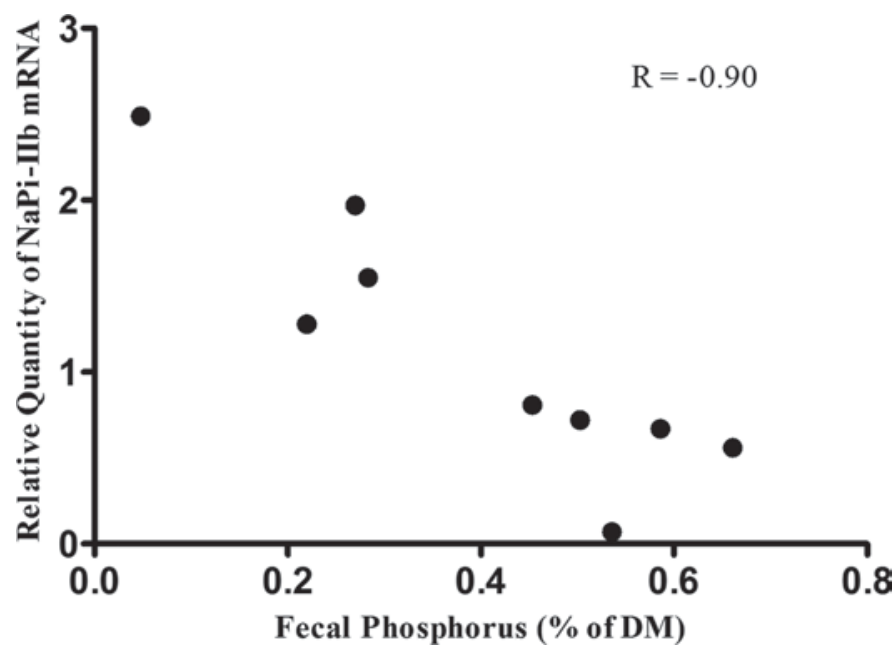

Figure 2. Correlation of expression of the phosphate transporter $\mathrm{NaPi}-\mathrm{IIb}$ in the distal jejunum to fecal phosphorus (\% of DM) of Holstein cows. A negative correlation $(\mathrm{R}=-0.90 ; P<0.0001)$ of $\mathrm{NaPi}-\mathrm{IIb}$ expression (normalized to GAPDH expression) and fecal $\mathrm{P}$ is present. Points on the graph represent the mean for the individual cows $(n=9)$. The number of experimental units varied due to the timing of collecting the intestinal samples, fecal samples, and operation of the abattoir.

mined using the relative quantification analysis with the LightCycler 480 software. A calibrator was included in all PCR runs to allow the normalization of ratios and comparison of experiments.

Fecal samples were obtained from the rectum of each cow and analyzed for DM (AOAC, 1990) and P. Fecal samples could only be obtained from 9 cows due to the timing of collecting the intestinal samples and operation of the abattoir. Phosphorus was analyzed using a modified method from Eaton et al. (1995). Dried fecal samples were ground to pass a $1-\mathrm{mm}$ screen and digested using a Kjeldahl sulfuric acid digest. A 1-mL sample was mixed with $12 \mathrm{~mL}$ of color-developing solution ( $43 \mu M$ ammonium molybdate, $0.33 \mathrm{~m} M$ antimony potassium tartrate, and $5.7 \mathrm{mM}$ ascorbic acid in $10 \mathrm{mM}$ $\mathrm{H}_{2} \mathrm{SO}_{4}$ ). Samples were incubated at room temperature for $45 \mathrm{~min}$ and absorbance at $880 \mathrm{~nm}$ was recorded. Phosphorus concentration was determined using a standard curve with external standardization (Eaton et al., 1995).

Ratios of NaPi-IIb to GAPD expression were analyzed using the MIXED procedure of SAS (SAS Institute Inc., Cary, NC). The effect of cow and section of small intestine were included in the model. The section of small intestine was included as a repeated measure within cow. Means were determined using the LSMEANS statement and when significant differences were detected, the PDIFF option was used to generate mean separations. Correlation was analyzed between fecal $\mathrm{P}$ concentration and $\mathrm{NaPi}-\mathrm{IIb}$ expression using
Proc Corr of SAS. Gene expression data more than 2 standard deviations from the mean were removed (1 observation for duodenum, 3 observations for proximal jejunum, 2 observations for distal jejunum, and 1 observation for ileum). Significant differences are noted at $P<0.05$.

Relative expression of $\mathrm{NaPi}$-IIb in the duodenum and proximal jejunum did not differ from zero $(P>0.68$; Figure 1). The NaPi-IIb expression was higher in the distal jejunum and ileum $(P<0.001)$; however, the distal jejunum and ileum were not significantly different from each other $(P>0.3)$. Distal jejunal NaPi-IIb mRNA (Figure 2) was highly correlated $(\mathrm{R}=-0.09 ; P$ $<0.0001)$ with fecal P concentration, and ileal NaPi-IIb expression (Figure 3 ) tended to correlate $(\mathrm{R}=-0.51$; $P=0.14)$ with fecal $\mathrm{P}$ concentration.

Data reported here for Holstein cows follows the general pattern observed in mice (Radanovic et al., 2005), where NaPi-IIb expression increases in the distal portions of the small intestine. Expression of $\mathrm{NaPi}-\mathrm{IIb}$ in goat small intestine is also similar to data from this experiment; NaPi-IIb is absent in the duodenum and higher in the jejunum (Huber et al., 2002). No data are available on ileal NaPi-IIb expression in goats. Shirazi-Beechey (1988) reported that $\mathrm{Na}^{+}$-dependent $\mathrm{P}$ absorption occurs only in the duodenum of rabbits. It is evident that a species difference exists in tissue specificity of NaPi-IIb expression; however, segmental expression in Holstein cattle appears to be similar to that in mice and goats. In those species, NaPi-IIb is present in

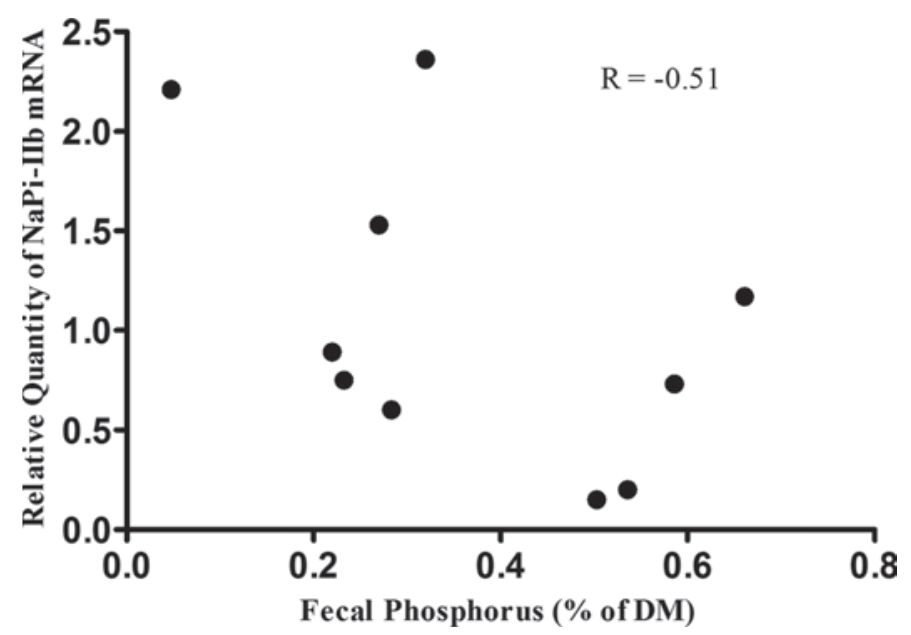

Figure 3. Correlation of expression of the phosphate transporter $\mathrm{NaPi}-\mathrm{IIb}$ in the ileum to fecal phosphorus (\% of DM) of Holstein cows. A slight negative correlation $(\mathrm{R}=-0.51 ; P=0.14)$ of $\mathrm{NaPi}-\mathrm{IIb}$ expression (normalized to GAPDH expression) and fecal phosphorus is present. Points on the graph represent the mean for the individual cows $(n=10)$. The number of experimental units varied due to the timing of collecting the intestinal samples, fecal samples, and operation of the abattoir. 
distal portions of the small intestine where inorganic $\mathrm{P}$ concentration is lower and the transport system is less likely to become saturated. The observation in the present study that the expression of NaPi-IIb increases in distal portions of the small intestine of Holstein cows is opposite of observations in chickens, where $\mathrm{NaPi}-\mathrm{IIb}$ expression is highest in proximal portions of the small intestine and lower in the distal small intestine (Yan et al., 2007). The species difference could be due to several factors, including anatomical and physiological differences in the gastrointestinal tract, contrasts in $\mathrm{P}$ requirements per unit of metabolic body weight, or the presence of other $\mathrm{P}$ transporters yet to be discovered.

Previous research in bovines has shown that fecal $\mathrm{P}$ varies with intake of dietary $\mathrm{P}$ (Barrow and Lambourne, 1962; Wadsworth and Cohen, 1976). Additionally, several studies have also demonstrated that fecal $\mathrm{P}$ concentration can be affected by factors such as milk production and dietary fiber source (Morse et al., 1992; Dou et al., 2002; Wu, 2005). High concentrations of P in the gastrointestinal tract of Holstein cows, as indicated by higher fecal $\mathrm{P}$, were correlated with lower expression of NaPi-IIb mRNA in the epithelium of the small intestine. However, it is not clear if the expression of $\mathrm{NaPi}-\mathrm{IIb}$ is the cause or the result of fecal P concentration. Radanovic et al. (2005) demonstrated that dietary $\mathrm{P}$ restriction resulted in an increase in NaPi-IIb mRNA in mice (Radanovic et al., 2005). Dietary P restriction in goats resulted in an increase in $\mathrm{NaPi}$-IIb protein quantity but not mRNA concentration (Huber et al., 2002), suggesting that post-transcriptional regulation of phosphate transporter protein synthesis or stability may also occur. It is not clear if this increase in mRNA (in mice) or protein quantity (in goats) resulted in a greater capacity to absorb $\mathrm{P}$, but it has been shown that lower dietary $\mathrm{P}$ concentrations results in enhanced $\mathrm{P}$ absorption in chicks (Fox and Care, 1978b) and pigs (Fox and Care, 1978a). Upregulation of this phosphate transport absorption could play a role in the increased absorption.

Species-specific differences in the regulation of NaPiIIb expression in the small intestine exist, and little is known about the regulation of expression in cattle. Further research to increase the understanding of the regulatory mechanisms related to $\mathrm{NaPi}-\mathrm{IIb}$ expression in the small intestine of dairy cattle would potentially allow for a decrease in fecal $\mathrm{P}$ excretion from dairy cattle and contribute to decreasing the environmental costs associated with dairy production.

\section{REFERENCES}

AOAC. 1990. Official Methods of Analysis. 15th ed. Assoc. Off. Anal. Chem., Arlington, VA.
Barrow, N. J., and L. J. Lambourne. 1962. Partition of excreted nitrogen, sulphur, and phosphorus between the faeces and urine of sheep being fed pasture. Aust. J. Agric. Res. 13:461-471.

Breves, G., and B. Schröder. 1991. Comparative aspects of gastrointestinal phosphorus metabolism. Nutr. Res. Rev. 4:125-140.

Chomczynski, P., and N. Sacchi. 1987. Single-step method of RNA isolation by acid guanidinium thiocyanate-phenol-chloroform extraction. Anal. Biochem. 162:156-159.

Cross, H. S., H. Debiec, and M. Peterlik. 1990. Mechanism and regulation of intestinal phosphate absorption. Miner. Electrolyte Metab. $16: 115-124$.

Danisi, G., and H. Murer. 1991. Inorganic phosphate absorption in small intestine. Page 323-336 in Handbook of Physiology. Vol. 4. Am. Physiol. Soc., Bethesda, MD.

Dou, Z., K. F. Knowlton, R. A. Kohn, Z. Wu, L. D. Satter, G. Zhang, J. D. Toth, and J. D. Ferguson. 2002. Phosphorus characteristics of dairy feces affected by diets. J. Environ. Qual. 31:2058-2065.

Eaton, A. D., L. S. Clesceri, and A. E. Greenberg. 1995. 4500-P.E. Ascorbic acid method. Pages 146-147 in Standard Methods For The Examination of Water And Wastewater. 19th ed. A. Eaton, L. S. Clesceri, and A. Greenberg, ed. American Public Health Association, Washington, DC.

Fox, J., and A. D. Care. 1978a. Effect of low calcium and low phosphorus diets on the intestinal absorption of phosphate in intact and parathyroidectomized pigs. J. Endocrinol. 77:225-231.

Fox, J., and A. D. Care. 1978b. Stimulation of duodenal and ileal absorption of phosphate in the chick by low-calcium and low-phosphorus diets. Calcif. Tissue Res. 26:243-245.

Helps, C., H. Murer, and J. McGivan. 1995. Cloning, sequence analysis and expression of the cDNA encoding a sodium-dependent phosphate transporter from the bovine renal epithelial cell line NBL-1. Eur. J. Biochem. 228:927-930.

Huber, K., C. Walter, B. Schroder, J. Biber, H. Murer, and G. Breves. 2000. Epithelial phosphate transporters in small ruminants. Ann. N. Y. Acad. Sci. 915:95-97.

Huber, K., C. Walter, B. Schröder, and G. Breves. 2002. Phosphate transport in the duodenum and jejunum of goats and its adaptation by dietary phosphate and calcium. Am. J. Physiol. Regul. Integr. Comp. Physiol. 283:R296-R302.

Kayne, L. H., D. Z. D'Argenio, J. H. Meyer, M. S. Hu, N. Jamgotchian, and D. B. Lee. 1993. Analysis of segmental phosphate absorption in intact rats. A compartmental analysis approach. J. Clin. Invest. 91:915-922.

Kayne, L. H., P. C. Pham, P. T. Pham, and D. B. Lee. 2001. Intestinal absorption of phosphate. Pages 355-362 in Massry and Glassock's Textbook of Nephrology. 4th ed. S. G. Massry and R. J. Glasscock, ed. Lippincott Williams \& Wilkins, Philadelphia, PA.

Morse, D., H. H. Head, C. J. Wilcox, H. H. Van Horn, C. D. Hissem, and B. Harris Jr. 1992. Effects of concentration of dietary phosphorus on amount and route of excretion. J. Dairy Sci. 75:30393049 .

Murer, H., I. Forster, and J. Biber. 2004. The sodium phosphate cotransporter family SLC34. Pflugers Arch. 447:763-767.

Radanovic, T., C. A. Wagner, H. Murer, and J. Biber. 2005. Regulation of intestinal phosphate transport I. Segmental expression and adaptation to low-Pi diet of the type IIb $\mathrm{Na}^{+}-\mathrm{Pi}$ cotransporter in mouse small intestine. Am. J. Physiol. Gastrointest. Liver Physiol. 288:G496-G500.

Shirazi-Beechey, S. P. 1988. Phosphate transport in intestinal brushborder membrane. J. Bioenerg. Biomembr. 20:273-288.

Wadsworth, J. C., and R. D. H. Cohen. 1976. Phosphorus utilisation by ruminants. Rev. Rural Sci. 3:143-153.

Werner, A., and R. K. H. Kinne. 2001. Evolution of the Na-Pi cotransport systems. Am. J. Physiol. Regul. Integr. Comp. Physiol. 280:R301-R312.

Wu, Z. 2005. Utilization of phosphorus in lactating cows fed varying amounts of phosphorus and sources of fiber. J. Dairy Sci. 88:2850-2859.

Yan, F., R. Angel, and C. M. Ashwell. 2007. Characterization of the chicken small intestine type IIb sodium phosphate cotransporter. Poult. Sci. 86:67-76. 